ment on such flights. In addition to the the need for education for childbirth.-We U.K., many flights have been undertaken to are, etc.,

Europe, to such places as Copenhagen, Paris, and Majorca. At the present time the air wing is limited to sitting cases in its own aircraft and chanters air ambulances for stretcher cases. It is hoped that an aircraft may be made available to us in the future for the carriage of stretcher cases. If any of your readers are able to help us in this respect it will enable us to reduce the cost to the patient even further.

All pilots, controllers, and medical and nursing air attendants give their time free, the only expense involved being the running cost of the aircraft and odd items such as landing fees. We shall be pleased to supply further information to any interested readers. - I am, etc.,

D. H. ClaRk

St. John Air Wing,

St. Margaret's Hospital,
Epping, Essex

\section{Active Management of Labour}

SIR,-Recent letters on this subject (11 August, p. 352, and 25 August, p. 453) have given us no reason to alter the opinion that pain in labour is an emotive subject.

In our paper (21 July, p. 135) we sought to emohasize that the problem of pain in labour should not be considered in isolation; we did not dispute that labour is often painful or that epidural block provides a highly effective method of pain relief, and we further recognize that it may not have been sufficiently utilized in our patients. This is, however, a far cry from the suggestion by Professor Selwyn Crawford (25 August, p. 453) that epidural anaesthesia should be recommended to all patients, even to multigravidae before labour has started.

When the results of epidural anaesthesia in labour are evaluated the total welfare of mother and child must be considered and this must at least include an explicit account of perinatal deaths, necropsy examinations, and cases of possible brain damage. To take one important example, between 1963 and 1970 there were 17 perinatal deaths from traumatic intracranial haemorrhage, proved at necropsy, among first-born infants with cephalic presentations in this hospital. Fifteen were delivered with forceps. The incidence of fatal head injury was almost 100 times as high in infants delivered by forceps. Even the most enthusiastic supporters of epidural anaesthesia concede a high incidence of forceps, particularly in primigravidae, and the implications of this for both mother and child have not received nearly enough attention.

The responsibility for mother and child in labour rests with the obstetrician, and the problem of pain is only one, albeit important, aspect of his care in which safety must take precedence above all else. The place of epidural anaesthesia in first labours is not yet clear, but it can be evaluated only in a situation where the management of labour is under strict control and all other important factors are taken into account. We are presently engaged in an attempt at objective assessment of this and the results will be published in due course.

In conclusion we regret Professor Crawford's reference to Grantly Dick Read, who did so much to advance our appreciation of
KIERAN O'DRISCOLL JOHN M. STRONGE

National Maternity Hospital,
Dublin

\section{Irradiation of C.N.S. in Leukaemia}

SIR,-I feel that I must take issue with the arbitrary way in which Dr. D. G. McGowan (21 July, p. 170) has selected certain figures from the St. Tude (Memphis) Total VI study in order to question the early results of the Medical Research Council study (19 May, p. 381) and the value of prophylactic treatment of the central nervous system in childhood leukaemia in general. I am sure there will be commen from the writers of the M.R.C. report, and I will therefore restrict mine to the data he has culled from the St. Jude Total VI study.

In questioning the effects of this treatment on survival Dr. MaGowan ignores the fact that the St. Jude group has repeatedly stressed, and elegantly demonstrated ${ }^{1}$ that early survival figures (that is, about four years from the start of the trial from which he quotes) are misleading. With curren therapy it is possible to keep many patient alive for prolonged periods through several relapses, even though they will eventually die. Patients who relapse after adequate treatment have infrequently become longterm survivors. Since "we are now thinking in terms of cure," to quote his own words, he should use the continuous complete remission rate, which is the quickest and most reliable index of long-term leukaemia-free survival. The figures of $30 / 45(66 \%)$ survivors in the prophylactic treatment group and $29 / 49(60 \%)$ in the non-prophylactic group which he quotes are very misleading when compared with the published continuous complete remission rates of 29/45 $(64 \%)$ and $11 / 49(22 \%)$ respectively for the holds true for the haematological relapse rates referred to in his second question

When Dr. McGowan turns to the effects of C.N.S. prophylaxis on C.N.S. leukaemia in the same study he quotes figures of $3 / 45$ $(6.7 \%)$ of patients in the prophylactic treatment group subsequently developing C.N.S. leukaemia. He then compares this with figures from a much earlier report for the non-prophylactic group of $5 / 47 \quad(10.6 \%)$ treated for C.N.S. disease who had subsequently had C.N.S. recurrence (two patient excluded who were actually receiving radiation for C.N.S. disease). The data published by the St. Jude group ${ }^{1}$ show that at a time when $2 / 45(4.4 \%)$ of the prophylactically treated group had developed C.N.S. disease, 46 months from the onset of the study, $32 / 49(65.3 \%)$ of the non-prophylactic group had developed C.N.S. disease, and only 15 of the 32 C.N.S.-relapsed patients remained in a second complete remission, $9 / 17(>50 \%)$ second relapses having involved the C.N.S. despite therapeutic radiaeloquently for themselves, it is surely statistical nonsense to comoare the percenlactic radiation early with those given therapeutic radiation much later without taking account of the very substantial difference in time at risk of developing same groups of patients. ${ }^{1}$ The same argument tion. Even if these figures did not speak so tage of relapses in one group given prophy-
C.N.S. disease subsequent to radiation in the two groups.

Finally, there is the question of the potential hazards of C.N.S. radiation. These are, of course, a matter of considerable concern and debate, and no doubt we will all be relieved when someone finds an effective and less potentially toxic form of prophylactic treatment, or an effective form of therapeutic treatment, so that the $20 \%$ of patients who will not develop C.N.S. disease in the long term may be spared unnecessary treatment. As things stand at present, however, prophylactic C.N.S. radiation has revolutionized the treatment of childhood acute lymphoblastic leukaemia and provided the prospect of eradication of the disease in the majority of cases. It will require strong grounds indeed to justify ethically the withholding of this treatment from the current generation of patients, even if some of them do develop the potential complications mentioned, until an effective substitute has been found.-I am, etc.,

M. G. Motr

University Department of Child Health,

Royal Hospital for Sick Children,

Simone, J., Aur, R. J. A., Hustu, H. A., and

Economics of Varicose Veins

SIR,-In your leading article (16 June, p. 626) you state that "because sclerotherapy can be undertaken on an outpatient basis, patients usually prefer it to surgical treatment. It is an economic help to them, for they can continue with normal activities while under treatment. Another advantage is that pressure on expensive bed and theatre time is reduced."

As a result of experience with more than 4,000 stripping operations for varicose veins the length of hospital stay has been decreased so that stripping procedures can now be performed on a fully ambulatory basis. Five hundred patients have been operated upon on an ambulatory basis. ${ }^{1}$ The patient is admitted to the hospital at 7.30 a.m. and discharged between 2 and 5 p.m. The operation is performed under a light general anaesthesia. The ambulatory technique minimizes postoperative morbidity. The patient is instructed to work and carry out all usual activities the day following surgery. With this technique there has been a great saving of hospital beds and work-hours lost to industry. Even before the ambulatory technique was started, about 3,500 patients were operated upon on a semi-ambulatory basis. The patient was admitted to the hospital the evening before surgery. Operation was performed the next morning and the patient discharged the same day or the following morning at the latest. An elastic support is necessary for 10-14 days following surgery, whereas with the injection-compression technique the bandage is used for much longer periods. Following operation, only abour two postoperative visits are necessary for suture removal or possible injections for residual varices.

Since surgery can now be performed on an ambulatory basis, it is especially importan to disregard economic factors and concentrate on specific indications. With marked valvular insufficiency and large varices ligation and stripping is more effective. Injection 
treatment is indicated when retrograde ven- PteGlu- $\left(2-{ }^{14} \mathrm{C}\right)$ in the first three days in ous pressure is not very marked. With both types of therapy the patient should be ambulatory since this is the best way to prevent complications. If each patient is individualized and treated according to specific indications, excellent results will be obtained both from injection therapy and from surgery. -We are, etc.

ROBERT A. NABATOFF David C. C. Stark

\section{New York}

1 Nabatoff, R. A., and Stark, D. C. C., American

\section{Suicidal Attempt with Propranolol}

SIR, - With reference to the letter from Drs. P. Karhunen and G. Härtel (21 April, p. 178) dealing with the effect of a massive dose of practolol on a healthy heart we would like to report a somewhat similar case of suicidal attempt with propranolol.

We have recently observed a man aged 45 with ocassional bouts of supraventricular dysrhythermia whioh had been treated with small doses of propranolol. In a suicidal attempt he took approximately 50 tablets of propranolol $(2,000 \mathrm{mg})$ and arrived in hospital two hours later in good general condition. A vial which had contained 50 tablets two days previously was found empty in his lodgings and fragments of tablets readily identifiable as propranolol were recovered on washing out his stomach. The blood propranolol level was not measured. His heart rate was $80 / \mathrm{min}$, pulse normal, blood pressure $120 / 80 \mathrm{~mm}$ Hg. E.C.G. showed normal sinus rhythm. He stayed in hospital for five days without any signs of cardiac disturbance.

Propranolol is known to possess the most potent negative inotropic and chronotropic activity of all beta-blockers. Nevertheless in our case a massive dose of propranolol produced no signs of depressive action on the heart. It seems therefore that the question of the effect of propranolol on the healthy heart needs to be reconsidered.-We are, etc.,

\section{W. WERMUT}

Szpital Morski, Gdynia, Poland

M. Wójcrck

\section{Formylation of Folate}

SIR,-We would like to comment on the paper of Drs. Janet Perry and I. Chanarin (9 June, p. 588) regarding folate absomption.

The synthesis of $\mathrm{H}_{4}$ PteGlu by dithionite reduction of PteGlu at $75^{\circ} \mathrm{C}$ does not give a pure product; it always contains $\mathrm{H}_{2}$ PteGlu, and possibly pteridine decomposition products. 1 Column chromatography does not permit unequivocal separation of the complex mixtures reported. In their own figures, the peaks for PteGlu and $\mathrm{H}_{2} \mathrm{PteGlu}$ overlap considerably and those for $5-\mathrm{CH}_{3}-\mathrm{H}_{4} \mathrm{P}$ teGlu are not in the same place on the two chromatograms.

The reduced folates were incubated for 1 hour at $37^{\circ} \mathrm{C}$ at very low concentrations and in the absence of an antioxidant. At $37^{\circ} \mathrm{C}$ in aqueous solution, with a partial $\mathrm{O}_{2}$ pressure of $104 \mathrm{~mm} \mathrm{Hg}$, the half life of H,PteGlu and tetrahydrobiopterin is $20-50 \mathrm{~min}^{2}$

The principal serosal material 10-formyl folate, ${ }^{3}$ fed to rats, showed no $5-\mathrm{CH}_{3}-\mathrm{H}_{4}$ liver, faeces, or urine, starving the animals for three days prior to the dose made no difference. Neither 10-CHO-PteGlu nor $10-\mathrm{CHO}-\mathrm{H}_{2} \mathrm{PteGlu}$ is reduced by dihydrofolic acid reductase. 5 Thus the alleged principal transport product is not converted to the major storage form of folates.

No mention is made of specific activity of the radioactive compounds isolated. In the absence of this information the microbiological assay reported means little since the large contribution of endogenous folate to the total cannot be calculated.

Smith et al. ${ }^{7}$ showed that folic acid transport occurred without metabolism as a prerequisite and this has been confirmed in a more recent paper.8 The results quoted by the authors are due to the oxidation of the endogenous tissue folate 10 formyl tetrahydrofolic acid to 10-formylfolic acid and have no relevance to the mechanism of transport of folic acid in the rat small intestine.-We are, etc.,

JoFn A. BLAIR

Department of Chemistry

University of Aston in Birmingham,

Dorset

Blakely, R. L., The Biochemistry of Folic Acid and Related Pteridines. Amsterda

Blair, Jorth-Holland Publ. Am, Tetrahedron Letters, 1973, No. 3, 203. Fournal of the Chemical Society. In press.

Beavon, J. R. G., and Blair, J. A., Analytical Biochemistry, 1971, 44, 335.

Beavon, J. R. G., and Blair, J. A. In preparation Biochemistry, 1965, 4, 839.

Biochemistry.' R66, 5,3878 and Nichol, C. A Siochemistry, 1966, 5, 3878 Biochimica et Biophysica Acta, 1970, 219, 37. A. Binder, H. J., Olinger, B. J.; and Bertino, J.R.,
Gastroenterology, 1973, 64, 700 .

\section{Detection of Hypertension in Childhood}

SIR,-I beg to guestion the assumption, upon which your leading article (18 August, p. 365) seems to rest, that essential hyper tension is a distinct disease entity of which ably be discussed.

Essential hypertension is diagnosed by exclusion of all known causes of hypertension. We may well have to accept that it may be impossible to discover all the factors which produce it. The causes may vary with each individual case; they may be diverse and interrelated (genetic, biochemical, psychological, etc.). At present we can but consider essential hypertension as a clinical sign of some disturbance of normal homoeostasis whose nature we do not understand. It follows that what your article implies by prophylaxis and treatment really relates to the modification of symptoms and signs of a complex morbid process which cannot be totally avoided or healed. The only available treatment is symptomatic. Symptomatic treatment will often leave the causes of the illness unaffected. It can be considered prophylactic only if it be maintained indefinitely in onder to effect some degree of reduction of the potential morbidity of the disease process.

It seems to me that whereas the treatment of the causes of illness may be a matter for public concern and for screening, the treat-
Sherborne School

J. R. G. BEAvoN the early preventive treatment may justifi- ment of symptoms can be ethically justified only by the specific request of the individual Symptomatic treatment does not heal; it only pretends to do so. To offer symptomatic treatment in the later years of life seems humane and may even be considered good medicine; but I find horrifying the thought of advising a hypertensive young person to "improve" the rest of his life with drugsor even special dieting-without the full cognizance and active request of that individual or his legal guandian.

Your article gives the imoression that the persuasive introduction of symptomatic prophylactic measures against hypertension may in future be justified in terms of economics and acceptance as beneficial by the medical profession. I submit that there is more to it than that.-I am, etc.,

Warlingham Park Hospital,

J. F. GORDON Surrey

SIR,-In your leading article (18 August, p. 365) you state that "if the treatment of hypertension in young adults comes to be accepted as beneficial .. . the screening of 20-year-olds will be easily justified." Screening of that age group would be difficult Assuming that raised blood nressure in childhood means hypertension in adult life, then it would be easy to identify children with a raised blood pressure prior to leaving school. School medical staff could fit this into the present medical examinations. The names of those found at school to have a raised blood pressure would be sent to the relevant family doctor. N.H.S. records of these children would be identified by a suitable symbol on the envelope with the year that the patient attains the age of 20 . In that year, the family doctor, or possibly the health visitor in a practice with such an attachiment, would re-check the blood pressure and treatment would be instituted if necessary.

I feel this to be a practical way in which potential hypertensives could be identified without the difficulty of examining every young adult, and one in whioh the school health service could make a valuable contribution. I suggest that a pilot scheme be begun in the area of one health authority.-I am, etc.,

Wareham, Dorset

W. E. HADDEN

\section{Aspirin in Prophylaxis of Ischaemic} Feart Disease

SIR,-It is now five years since O'Brien' published his paper on the "Effects of Salicylates on Fuman Platelets" which showed that asnirin inhibited adenosine diphosphate (ADP) release from platelets. This release contributes to the adhesion of platelets and is increased by adrenaline. If Duguid's hyoothesis that an intimal tear and platelet agoregation are the first steps in the develooment of the atherosclerotic plague is correct, aspirin might protect against the develooment of atherosclerosis. Aspirin might also be expected to reduce the likelihood of thrombosis occurring in an atherosclerotic artery. Adrenaline plays a part in inducing platelet aggregation; in particular it induces a second wave of closer and firmer aggregation. Aspirin abolishes this second 